\title{
THE USE OF FENTANYL IN THE OPERATIVE AND POSTOPERATIVE PERIOD, WITH REFERENCE TO METHOXYFLURANE
}

\author{
J. W. R. MCINTYRe, F.F.A.R.C.S., J. D. M. MilleR, M.D., F.R.C.P.(C), AND \\ P. CORKERY, M.B., B.CH. ${ }^{*}$
}

The pharmacological properties of methoxyflurane have ensured it a place in the current practice of anaesthesia. However, its physical characteristics cause slow induction and necessitate cessation of administration prior to the termination of surgery. Moreover, as is the case with other halogenated agents, adequate anaesthesia occasionally seems unavoidably associated with cardiovascular depression. For many years analgesics administered intravenously have been employed to supplement an inahlational agent, usually nitrous oxide. It seemed possible that the use of intravenous analgesics might facilitate methoxyflurane administration and reduce the quantity required. Thus methoxyflurane in minimal quantities would become a versatile and easily transportable substitute for nitrous oxide. Fentanyl was selected as the analgesic supplement. This drug is a 4-anilo piperidine derivative related to meperidine and phenoperidine. Animal studies have shown its analgesic effects to be many times more potent and of shorter duration than morphine. Its emetic effects are minimal, and doses in excess of a recommended human dose have little effect on the pulse rate and blood pressure in animals. ${ }^{1}$ Extensive clinical use has been reported. ${ }^{2}$

The object of the study presented here was to determine whether the use of intravenous increments of fentanyl during anaesthesia would permit maintenance of anaesthesia with quantities of methoxyflurane less than would otherwise be required, and whether fentanyl could be employed in the immediate postoperative period to produce a state in which the patient was adequately sedated but able to respond to normal nursing instructions. The method used was as follows.

Healthy normothermic patients routinely booked for daytime major abdominal surgery were accepted, and rejected only for reasons of hearing deficiency, lack of knowledge of the English language, or mental instability requiring drugs. The study was briefly explained to them, and they were told they would benefit medically from their co-operation. All the subjects were premedicated with atropine $0.6 \mathrm{mg}$. intramuscularly. Anaesthesia was induced with thiopentone $4 \mathrm{mg}$. per $\mathrm{kg}$. body weight, succinylcholine, and artificial ventilation 50 per cent in excess of the Radford Nomogram value for fifteen minutes with $4 \mathrm{~L} . / \mathrm{min}$. of oxygen containing 1.2 per cent methoxyflurane in a semi-closed circle absorber system. This latter drug was supplied from a Pentec vaporizer calibrated for the purpose by vapour chromatography and used throughout the study. It was separated from the circle system by a non-return valve. Maintenance of anaesthesia was by one of two methods:

1. Ventilation 50 per cent in excess of the Radford Nomogram value, with $4 \mathrm{~L}$./min. of oxygen containing methoxyflurane 0.34 per cent, until it was obvious

- Department of Anaesthesia, University of Alberta Hospital, Edmonton, Alberta. 
MCINTYRE et al.: FENTANYL IN THE OPERATIVE AND POSTOPERATIVE PERIOD 471

that this quantity of drug was and would be inadequate, in which case it was increased. It was, however, discontinued well before the termination of surgery, and these patients invariably responded to the suturing of the skin.

2. Ventilation 50 per cent in excess of the Radford Nomogram value, with $4 \mathrm{~L}$./min. of oxygen containing 0.34 per cent methoxyflurane, and supplemented with intravenous increments of fentanyl.

Gallamine was used to produce adequate relaxation, and strict criteria were used for the decision whether to administer a central depressant or a peripheral blocking agent. If there were movements of eyebrows, hand, or arm, or sustained rise in blood pressure or pulse rate, then a central depressant was administered, whereas the indication for the relaxant drug was inadequate muscle relaxation impeding the surgery. The surgery was uncomplicated and the patients remained in good condition. At its termination neostigmine $2 \mathrm{mg}$. and atropine $1.2 \mathrm{mg}$. were administered intravenously.

Two groups of patients, twenty male and twenty female took part, and anaesthetic techniques were selected by means of random numbers. ${ }^{3}$ After surgery was completed the patient was moved to the recovery room where for the following 60 minutes a prearranged routine was followed. Detailed observations regarding the patient's motor activity, spoken statements, pulse and blood pressure, were made on a protocol. Chest movements were recorded for the duration using a pneumograph and Electronics for Medicine PR-7 recorder. Questions to the patient regarding his identity and location were supplied through headphones at ten-minute intervals from a recorded tape, and these signals also recorded through a phono-channel on the PR-7 recorder. The voice was male, in a loud clear tone. Commands to take deep breaths and breathe more deeply were similarly given at ten-minute intervals. The headphones were worn continuously and reduced but did not eliminate the sounds of the environment. In an endeavour to avoid annoying repetition, once the patient had established his identity and location, a change was made to a tape track containing only a request to breathe. A plastic intravenous cannula was introduced during surgery, so that any required sedative drugs could be rapidly administered in the recovery room. Increments of fentanyl $0.02 \mathrm{mg}$. were used, and indications for this were motor behaviour of the patients or unsolicited comments on their sensations. The administrator was unaware of the anaesthetic technique that had been employed, and of the nature of the postoperative injection. In the first instance this was saline or fentanyl, selection for the case being based on random numbers, and a minimum of three minutes were permitted to elapse before a second injection was given. Normal nursing care, such as measuring the blood pressure, was confined to a period between stimuli in order to avoid artifacts and false responses. In analysis of the results chest movement response was determined by measuring the greatest inspiratory chest movement that occurred during a thirty-second period prior to the beginning of the stimulus, and comparing it with the ensuing thirty-second period. This was expressed as a percentage change. Control figures were obtained by using random numbers to select a point in time in which a theoretical stimulus might have been applied, and a percentage change calculated. A control was obtained in this way for each real stimulus applied.

Two or three days postoperatively the patients were visited by a person not 
otherwise involved in the investigation, and among the usual postoperative questions were some regarding memory of pre- and postoperative events as well as ideas regarding the patient's state of mind immediately following surgery. A selection of the opposing phrases described by Lasagna ${ }^{4}$ were used in an attempt to obtain a psychological profile of the patient's state of mind at that time.

\section{Results}

Some details of the age, weight, and duration of operation concerning the patients in the different groups appear in Table I. Statistical analysis of all the data revealed that the methoxyflurane and the methoxyflurane plus fentanyl groups were comparable with reference to age (analysis of variance $F=0.66$ ), weight (analysis of variance ( $F=4.38 ; p<0.01$ ): Duncan's Multiple Range and Multiple $\mathrm{F}$ test shows that the males (groups $\mathrm{A}+\mathrm{B}$ ) are significantly different from the females (groups $\mathrm{D}+\mathrm{C}$ ), mean weight of each group in kilograms, D 57.3 C 57.4 B 66.5 A 73.6, and duration of surgery (analysis of

TABLE I

\begin{tabular}{|c|c|c|c|c|}
\hline & \multicolumn{2}{|c|}{$\begin{array}{l}\text { Methoxyflurane } \\
\text { and fentanyl }\end{array}$} & \multicolumn{2}{|c|}{ Methoxyflurane } \\
\hline & group A & group C & group B & group D \\
\hline $\begin{array}{l}\text { Number of patients } \\
\text { Sex } \\
\text { Age (years) } \\
\text { Weight (kg.) } \\
\text { Duration (minutes) } \\
\text { Gallamine } \\
\text { (mg. } / \mathrm{kg} . / 30 \mathrm{~min} .)\end{array}$ & $\begin{array}{r}10 \\
\mathrm{M} \\
44-72 \\
54-101 \\
90-255 \\
0.37-0.66\end{array}$ & $\begin{array}{r}10 \\
F \\
18-80 \\
40-71 \\
85-230 \\
0.37-0.90\end{array}$ & $\begin{array}{r}10 \\
\mathrm{M} \\
33-73 \\
55-92 \\
60-300 \\
0.30-0.82\end{array}$ & $\begin{array}{r}10 \\
F \\
20-70 \\
48-70 \\
85-290 \\
\\
0.41-0.98\end{array}$ \\
\hline
\end{tabular}

variance between each group $F=0.50$, and combination of the groups $F=0.72$ ). There is no significant difference between gallamine dosage used in any of the groups (analysis of variance $F=1.60$ ). Although the character of the surgery was evenly divided between methoxyflurane and fentanyl and methoxyflurane groups, as far as distribution between sexes was concerned major urological and gynecological surgery tended to replace alimentary tract surgery.

The number of patients for whom anaesthesia could be maintained using a flow of $4 \mathrm{~L} . / \mathrm{min}$. containing 0.34 per cent methoxyflurane in a semi-closed circle absorber system was one out of twenty. With the addition of fentanyl, anaesthesia could be maintained in seventeen out of twenty iases. This is a significant difference $(p<0.01)$.

The dosage of fentanyl found necessary during surgery is shown in Figure 1, presented as drug requirement during a thirty-minute period in relation to body weight.

Following surgery the patients were taken to the recovery room, and in Table II is shown the period of time that had elapsed before the patients replied correctly to the question regarding their identity. The methoxyflurane plus fentanyl groups were aware of their identity significantly earlier than those in which 


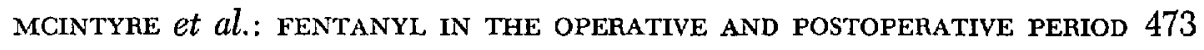

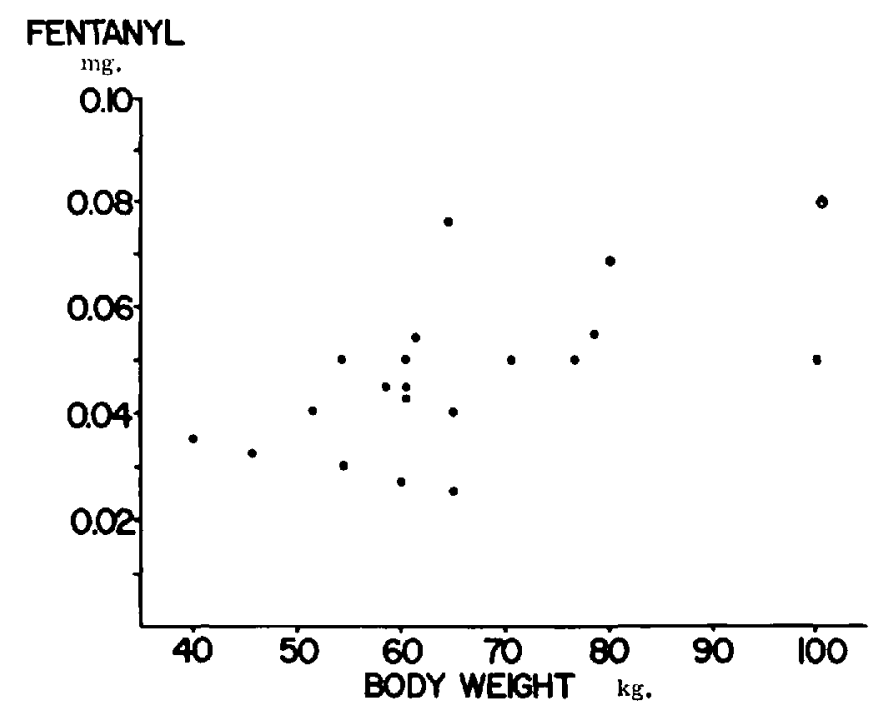

Figure 1. Fentanyl dosage during surgery expressed as $\mathrm{mg}$./30 minutes.

TABLE II

Times at Which Patients Established Identity

\begin{tabular}{ccccc}
\hline & \multicolumn{5}{c}{ Number of patients } \\
\cline { 2 - 5 } $\begin{array}{c}\text { Minutes after } \\
\text { anaesthesia }\end{array}$ & group A & group B & group C & group D \\
\hline 0 & 3 & 0 & 5 & 1 \\
10 & 4 & 1 & 3 & 0 \\
20 & 0 & 5 & 0 & 2 \\
30 & 1 & 0 & 0 & 2 \\
40 & 0 & 0 & 1 & 2 \\
50 & 0 & 2 & 0 & 1 \\
60 & 1 & 0 & 0 & 1 \\
$60+$ & 1 & 2 & 1 & 1 \\
\hline
\end{tabular}

methoxyflurane alone was used. (Analysis of variance $\mathrm{F}=6.73 ; 0.01<p<0.05$.) The results with reference to awareness of location were similar, the difference being that about ten minutes more elapsed before a correct reply was obtained.

Intravenous fentanyl $0.02 \mathrm{mg}$. was used for sedative purposes in the recovery room and in some cases the initial injection was saline. There was a significantly shorter mean time between requirements for sedation when the preceding injections had been saline than when they had been fentanyl (analysis of variance $\mathrm{F}=12.54 ; p<0.01$ ).

The fentanyl requirements during the hour observed in the recovery room are shown in Figure 2, presented in relation to the patient's body weight. Some patients required sedation prior to the time that they responded correctly to questioning, but there was little difference between the methoxyflurane and the methoxyflurane plus fentanyl groups in this respect. 


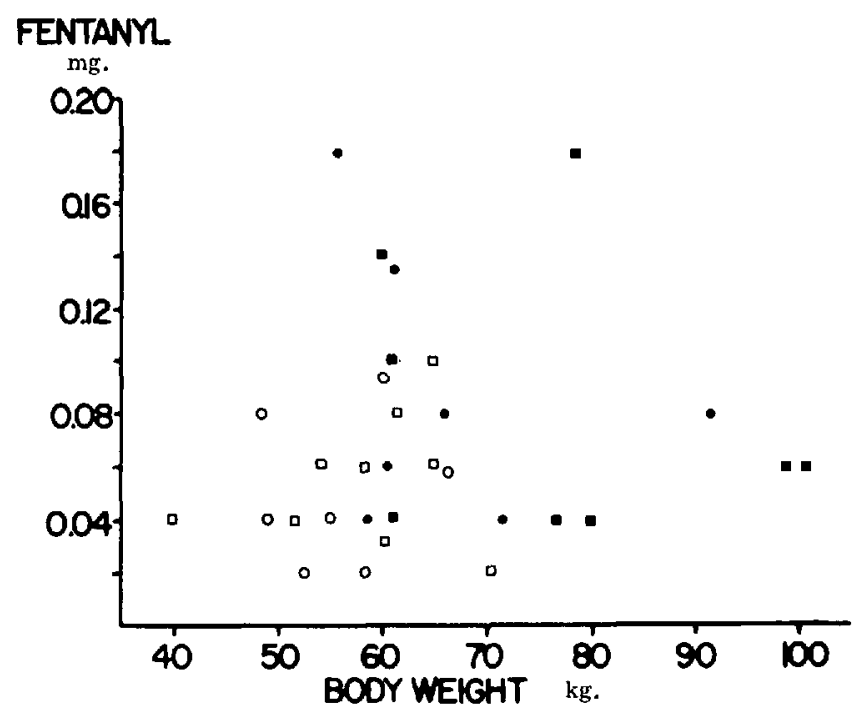

Ficure 2. Fentanyl dosage during the first postoperative hour. Circles represent methoxyflurane anaesthesia, squares represent anaesthesia with methoxyflurane and fentanyl. Open symbols represent females, solid symbols represent males.

Figure 3 represents the chest movement responses to command that occurred at the various time intervals in the males after the two forms of anaesthesia, and Figure 4 represents the same responses in the females. Control values are not shown. In the methoxyflurane-plus-fentanyl groups there was a significant response to stimulation at each time period beginning with ten minutes. When methoxyflurane alone had been used a significant difference in response to control does not appear until the sixty-minute stimulus. (Group $\mathrm{A}+\mathrm{C}$ Wilcoxon Parametric Paired Replicate Test for each time period beginning at 10 minutes; $p<0.01$.)

The pattern of these responses for the individual patients anaesthetized with methoxyflurane plus fentanyl appears in Figure 5 for males and in Figure 6 for females. A summary of the findings at the postoperative interview appears in Table III.

In discussion of these results, comments should first be made on the concentration of methoxyflurane used with fentanyl for maintenance of anaesthesia. This was stated to be $4 \mathrm{~L}$./min. of 0.34 per cent in a semi-closed absorber system. However, the precise quantities of methoxyflurane delivered to the patients in this study are not known, because although the non-return valve might reasonably be expected to attenuate the changes in vapour concentration produced in the vaporizer by artificial ventilation, there is no factual evidence for this. In addition Eger $^{5}$ has drawn attention to the possibility of rubber anaesthetic equipment acting as a reservoir for the drug. This is not considered a likely source of error here because of the extensive rotation of equipment in a large service, the relatively infrequent use of methoxyflurane, and the time period between the cases studied. 
MCINTYRE et al.: FENTANYL IN THE OPERATIVE AND POSTOPERATIVE PERIOD 475

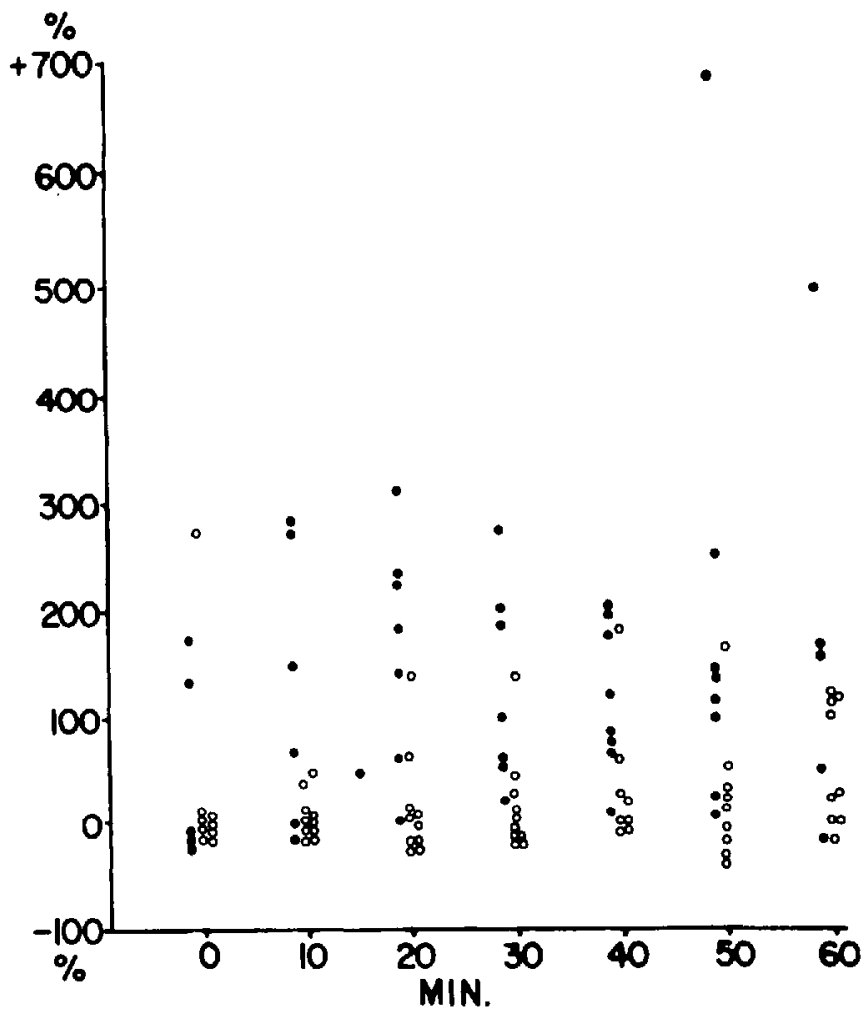

Figure 3. Male subjects recovering from anaesthesia. Maximum increase in chest expansion recorded within a 30-second period following the start of the request to breathe. Open circles represent methoxyflurane anaesthesia, solid circles represent anaesthesia with methoxyflurane and fentanyl.

TABLE III

Recollections of Subjective Sensations During the Immediate POStoperative Period

Figures refer to number of patients

\begin{tabular}{lcc}
\hline \hline & $\begin{array}{c}\text { Methoxyflurane } \\
\text { and fentanyl }\end{array}$ & $\begin{array}{c}\text { Methoxy- } \\
\text { flurane }\end{array}$ \\
\hline Mentally numb & 7 & 6 \\
Alert & 10 & 12 \\
Caln & 11 & 14 \\
Tense & 6 & 3 \\
Orientated & 11 & 12 \\
Disorientated & 6 & 3 \\
Pleasant & 6 & 7 \\
Tolerable & 6 & 4 \\
Unpleasant & 6 & 8 \\
Requests to breathe & 2 & 2 \\
\hline
\end{tabular}




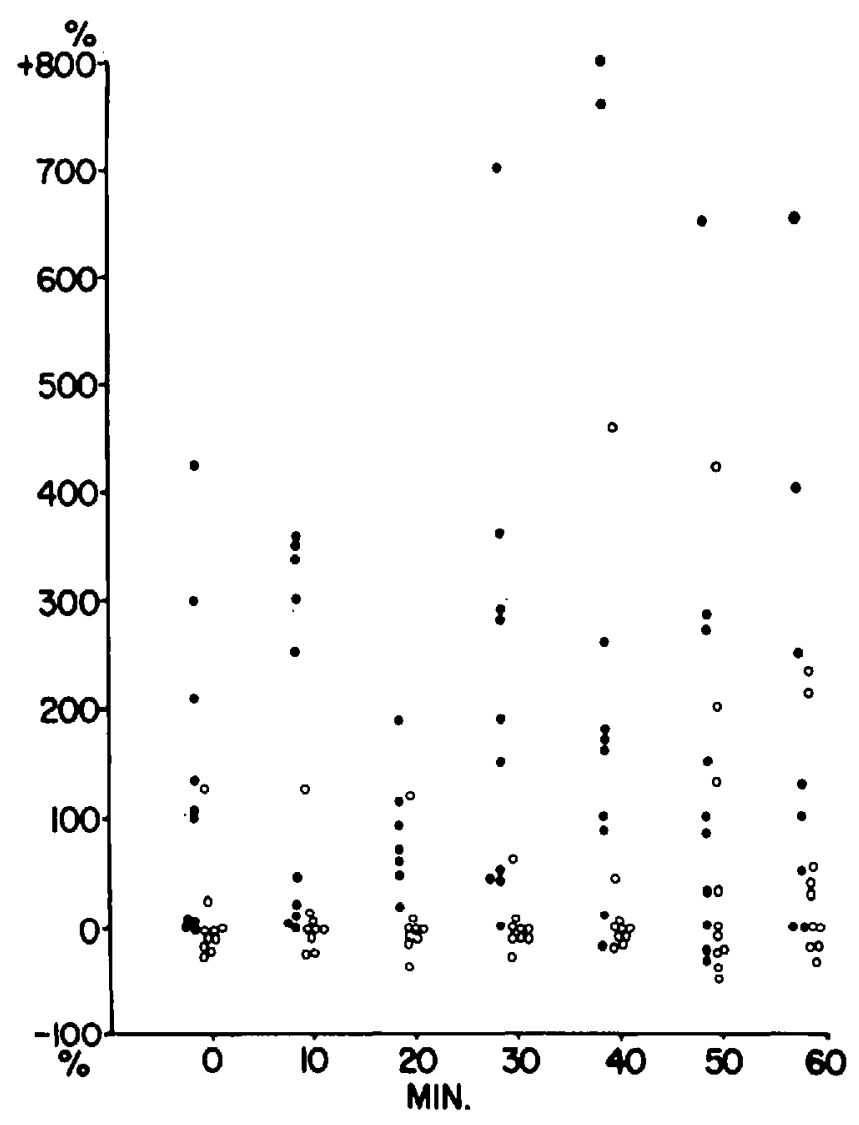

Figure 4. Female subjects recovering from anaesthesia. Maximum increase in chest expansion recorded within a 30 second period following the start of the request to breathe. Symbols as in Figure 3.

Valid comparisons cannot be made with values given in other clinical studies owing to differences in procedure. However, both Lambie ${ }^{6}$ and Dundee ${ }^{7}$ comment on the failure of methoxyflurane to produce a consistent rise in pain threshold in the absence of marked drowsiness. In view of the fact that in this study arousal rapidly followed the termination of methoxyflurane administration in the supplemented technique, it seemed likely that whatever part the methoxyflurane might play in producing analgesia, it played a greater part, relative to the fentanyl, in producing narcosis. The fentanyl dosage employed during surgery did not differ grossly from that used in the recovery room, at which time the patient could respond to auditory commands. The addition of fentanyl during surgery suppressed those motor responses that are customarily used in the assessment of anaesthetic depression, but it is possible that not all the afferent and efferent pathways were blocked. Other investigators have commented on the dissociation between responses to nociceptive and other sensory stimuli produced by fentanyl. ${ }^{8}$ Whether the subjects of the present study were anaesthetized or in a state of generalized analgesia was not assessed; but previous observations indicate that the latter might be the case. ${ }^{9}$ 
MCINTYRE et al.: FENTANXL IN THE OPERATIVE AND POSTOPERATIVE PERIOD 477

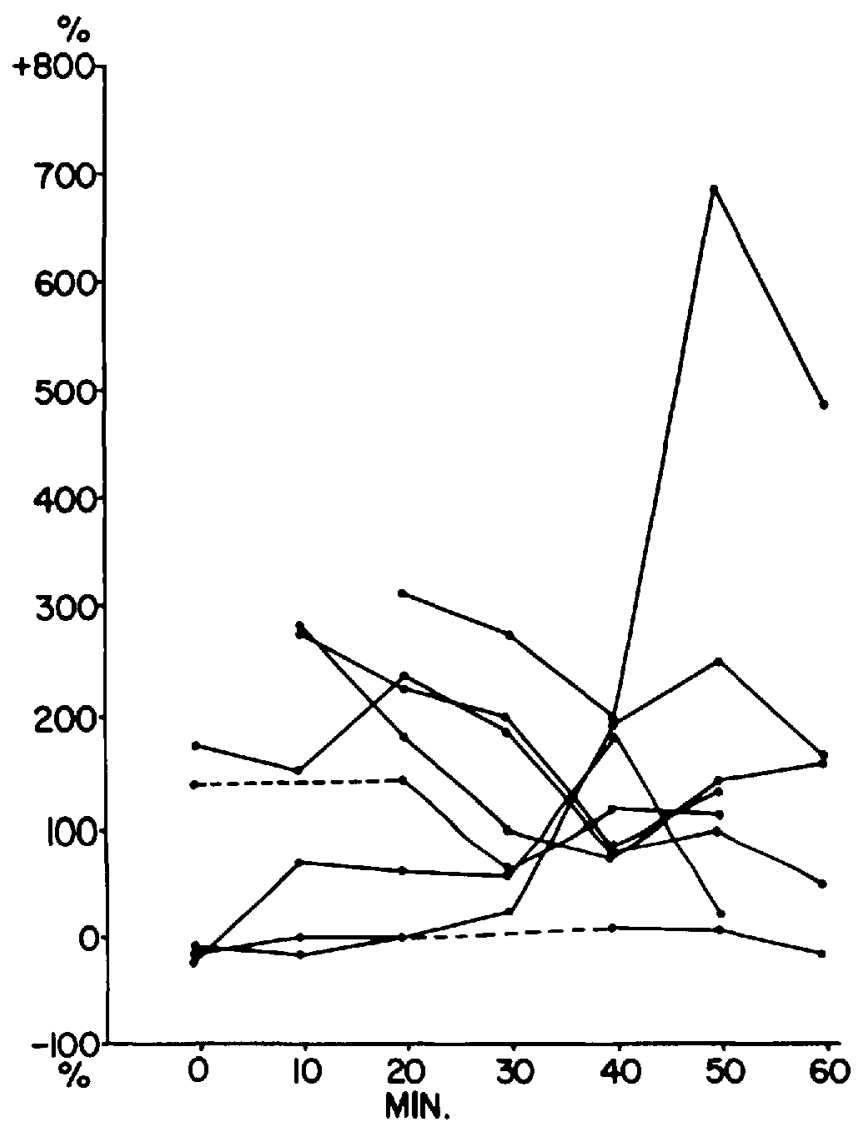

Figure 5. Serial chest expansion changes of individual male patients anaesthetized with methoxyflurane and fentanyl.

Prior to the study it was believed that the degree of postoperative analgesia was not significant in patients who had recovered consciousness from unsupplemented methoxyflurane anaesthesia, and it was thought that supplementation with fentanyl during surgery would be associated with an analgesic state on recovery of consciousness. The results showed that this was frequently the case, but not invariably so. This might be due to a rapid removal of the drug from sites of activity, but though the criteria for drug administration during surgery and in the recovery room were similar it cannot be assumed that these criteria always had the same cause. It is possible that fentanyl was being employed, albeit satisfactorily, for two or more different facets of its over-all effect concerning mood, drowsiness, and response to pain stimuli. The aetiology of postanaesthetic motor activity has been discussed by Eckenhoff ${ }^{10}$ and by Egbert. ${ }^{11}$ It can be due to the subconscious mind stimulated by a variety of afferent impulses, the respiratory state, and to the patient's preoperative psychological state. Many persons have stressed the value to the patients of reassurance, ${ }^{12,13}$ and the reduced postoperative drug requirements that this produces. Though the patients received a preoperative explanation, this study was more demanding of 


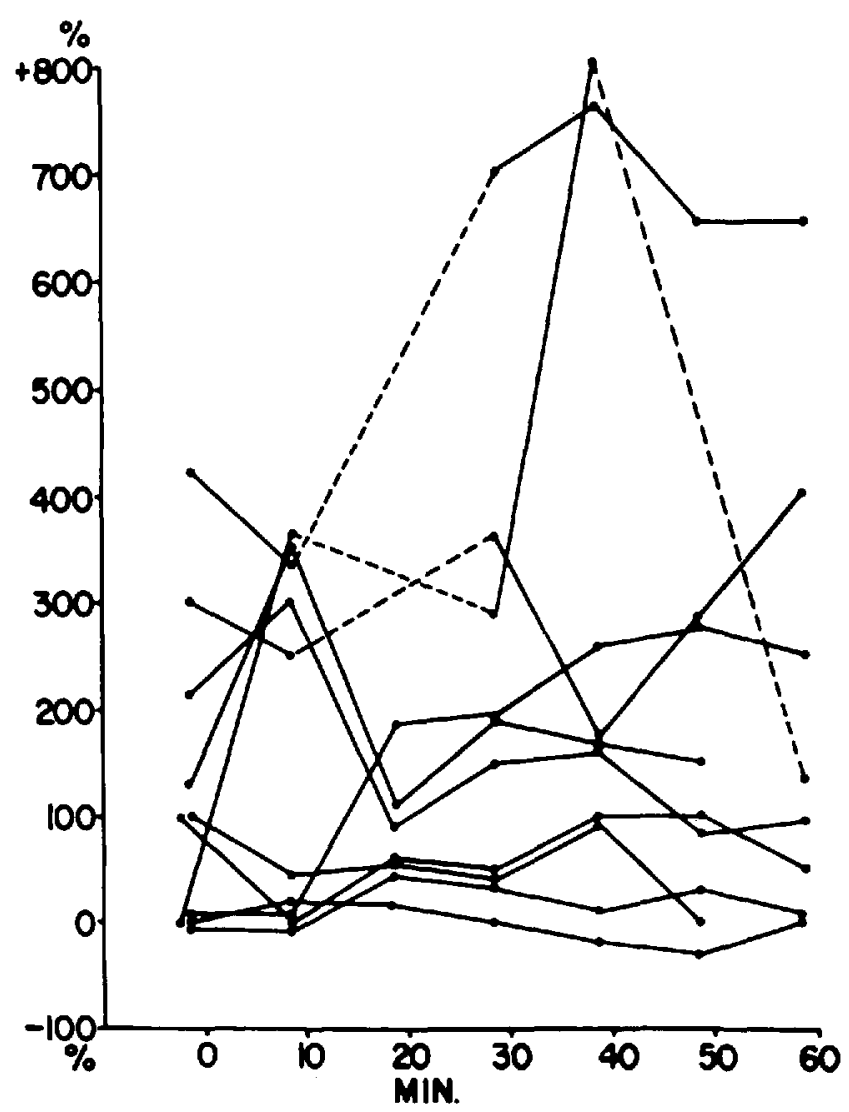

Figure 6. Serial chest expansion changes of individual female patients anaesthetized with methoxyflurane and fentanyl.

them in a number of respects than the regimen customarily employed in the recovery room. While a patient is semiconscious his name is to him the most significant auditory arousal stimulus, but technical difficulties precluded its use for this purpose, nor was tactile stimulation employed. Verbal encouragement was absent, and the request to breathe produced a situation that would necessitate maximum analgesic requirements. The intermittent intravenous injection of small doses of fentanyl was selected to avoid the variations of absorption from intramuscular sites, though the resultant uneven drug effect was appreciated, as well as the possible development of a rhythm of drug administration. However, continuous absorption from an intramuscular site would probably produce better results, and a dose of $0.025-0.05 \mathrm{mg}$. is presently in use.

Some aspects of the responses to requests to breathe are of interest. As can be seen from Figures 3 to 6 a value is not plotted for every patient at each time interval, because in some instances changing of cassettes and movements resulted in unsatisfactory recording. Severe restlessness did not occur but there appears to have been a higher incidence of artifacts in the male groups.

Examples of the responses appear in Figure 7. When the optimum response for the individual patient occurred, the maximum amplitude of chest movement 
MCINTYRE et $a l$. FENTANYL IN THE OPERATIVE AND POSTOPERATIVE PERIOD 479
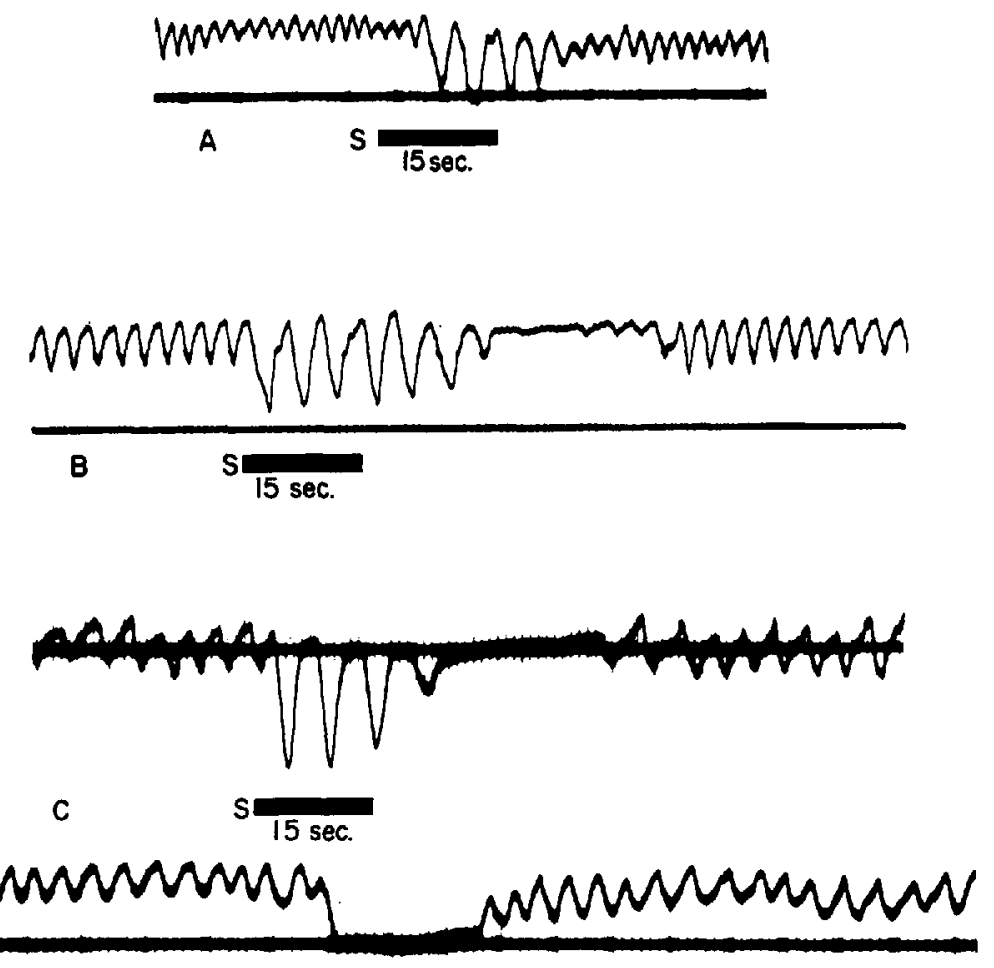

D

$15 \mathrm{sec}$.

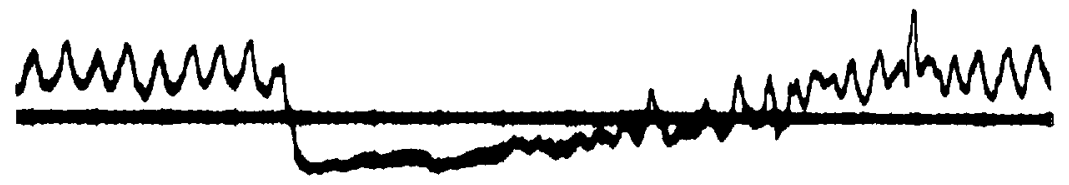

E

$15 \mathrm{sec}$.

monnumnummons

$F$

$$
\mathrm{S}
$$

$15 \mathrm{sec}$

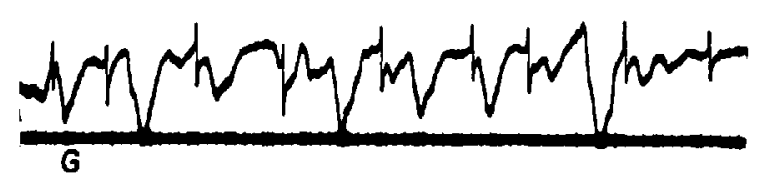

Figure 7. Examples of varying types of lower chest movement associated with requests to breathe $(S)$ in the postoperative period. Line $G$ shows hiccups interspersed with normal respiration. 
occurred at the first breath, and after four or five breaths the original amplitude was restored. Inspiration and expiration followed a normal pattern and it was assumed that the response was purposeful because at that time the patient was aware of his identity but had not necessarily responded correctly to questions about location. If the response was a vigorous one it was sometimes followed by a period of apnoea, after which the original movement was restored. This was a normal occurrence that might be enhanced by a raised threshold of carbon dioxide stimulation or the removal of a hypoxic chemoreceptor drive, and the activity of fentanyl possibly contributed to these periods of apnoea. Reported studies of a combination of fentanyl and droperidol indicate that responses to carbon dioxide stimulation are reduced. ${ }^{13}$

There was considerable variation in the measured response of each patient at varying times and probably contributing to this were the effects of any recently administered fentanyl and alterations in the pattern of respiratory activity. It should be emphasized that the relationship between expansion of the lower chest and respiratory function is a tenuous one. In the circumstances under consideration here a positive response to a request to breathe deeply is an indication of a number of factors, including the ability of the patient to hear and understand, a willingness to carry out the command, and an ability to carry out the command. Apart from the pharmacological effects of any drugs administered and the afferent stimuli brought into play by the chest movement, the psychological structure of the patient and his motivation are also of major importance.

The respiratory responses in all groups occurring prior to the patient's correct response to questions and sometimes afterwards were varied, and are represented in part by the negative values in Figures 3 to 6 . Examples appear in Figure 7 and include breath holding in inspiration and depression of respiration during the period of stimulus. These may be indicative of arousal and imperfect understanding of the commands. The deep breathing response to the command was undoubtedly associated with autonomic activity, but the respiratory responses just mentioned were considered manifestations of the startle reflex due directly or indirectly to the auditory stimulus and would also be associated with disturbances of the cardiovascular system. A hazard exists for the cardiac patient if the buffer reflexes of the cardiovascular system fail to control the effects of pain or psychologic stress and the inadvertent demonstration in this study of one facet of the startle reflex is a reminder that patients should not be subjected to sudden strong stimuli, or alternatively, these reflexes should be attenuated.

This study provided little information regarding emotional or other subjective experiences during recovery, because these cannot be inferred from motor behaviour. Postoperative interviews were complicated by the difficulty some patients had in comprehending the questions and making the required comparisons. If the recollections expressed by the patients did refer to the immediate postoperative period, then those of the group anaesthetized with methoxyflurane alone would refer to their ward environment rather than the recovery room. Thus, though observations such as this are of interest, no definite conclusions can be drawn from them. It was established that no recollection of anything that could be interpreted as a hallucinatory experience occurred, and only four out of 
MCINTYRE et al.: FENTANYL IN THE OPERATIVE AND POSTOPERATIVE PERIOD 481

forty patients remembered the requests to breathe. A surprising number considered their experience to have been a pleasant one and this was attributed in part to rapport with the interviewer.

In conclusion, fentanyl administered in association with methoxyflurane reduces the requirements of the latter drug, and facilitates its use. Fentanyl appeared to have no significant cardiovascular effects in the recumbent patient, nor was there evidence of emetic qualities, or histamine release at the site of injection. Like other potent analgesics it is a respiratory depressant, a property disadvantageous in the postoperative period but useful during surgery if artificial control of ventilation is rapidly required without the use of neuromuscular blocking drugs. Its brevity of action is an attribute in this respect. In the postoperative period fentanyl is an effective analgesic while retaining the ability of the patient to co-operate with nursing management.

\section{SUMMARY}

Comparable groups of adult patients undergoing abdominal surgery were anaesthetized with methoxyflurane alone or supplemented with fentanyl. It was found that fentanyl reduced methoxyflurane requirements and that $4 \mathrm{~L} . / \mathrm{min} . \mathrm{O}_{2}$ containing 0.34 per cent methoxyflurane in a semi-closed circle absorber system was almost invariably adequate for maintenance.

Patients were observed for one hour postoperatively and it was found that the supplemented group recovered consciousness more rapidly and were better able to respond to auditory commands. There was evidence that the startle reflex is active under certain circumstances during the early stages of recovery of consciousness. Fentanyl could be used satisfactorily to relieve distress in the postoperative period.

Interviews during the convalescent period established the absence of any experiences that might be termed hallucinatory. Only four out of forty patients had any recollection of their experiences in the recovery room.

\section{RÉSUMÉ}

Des groupes semblables d'adultes subissant une opération abdominale ont été anesthésiés au méthoxyflurane seul ou additionné de fentanyl. On a observé que le fentanyl diminuait la dose requise de méthoxyflurane et qu'un débit de 4 litres d'oxygène par minute contenant 0.34 pour cent de méthoxyflurane en circuit semi-fermé avec absorption de $\mathrm{CO}_{2}$ était presque toujours suffisant pour le maintien de l'anesthésie.

Après l'opération, on a observé les malades durant une heure et on a trouvé que ceux qui avaient reçu du fentanyl devenaient conscients plus rapidement et pouvaient mieux répondre aux ordres qu'on leur donnait. Il est apparu que le réflexe de la peur est actif dans certaines circonstances au début du retour de la conscience. Le fentanyl pourrait être utilisé avec satisfaction pour diminuer linquiétude durant la période postopératoire. 
Durant la convalescence, nos conversations avec les malades ont prouvé qu'ils n'avaient souffert d'aucune hallucination. Quatre seulement sur quarante malades avaient gardé quelque souvenance de leur passage à la salle de réveil.

\section{ACKNOWLEDGMENTS}

Gratitude is expressed to Miss L. Galenza, R.N., and her recovery room staff whose willing and effective co-operation contributed greatly to this study.

\section{REFERENCES}

1. Gardocki, F. F. \& Yelnoski, J. A Study of Some of the Pharmacological Actions of Fentanyl Citrate. Toxicol. \& Appl. Pharmacol. 6: 48 (1964).

2. Prys-Roberts, C. \& Kelman, G. R. The Influence of Drugs Used in Neurolept Analgesia on Cardiovascular and Ventilatory Function. Brit. J. Anaesth. 39: 134 (1967).

3. Fisher, Ronald A. \& Yates, Frank. Statistical Tables for Biological, Agricultural and Medical Research. 3rd ed., London: Oliver \& Boyd (1948).

4. Lasagna, Louis; von Felsinger, John M.; \& BeEcher, Henry K. Drug-Induced Mood Changes in Man. J.A.M.A. 157: 1006 (1955).

5. Eger, Edmund I., II \& Brandstater, Bernard. Solubility of Methoxyllurane in Rubber. Anesthesiology. 24: 679 (1963).

6. Lambie, R. S. The Analgesia of Methoxyflurane. Canad. Anaesth. Soc. J. 10: 469 (1963).

7. DundeE, John W. \& Love, William J. Alteration in Response to Somatic Pain Associated with Anaesthesia: XIV. Effects of Subnarcotic Concentrations of Methoxyflurane. Brit. J. Anaesth. 35: 301 (1963).

8. Nilsson, E. \& Incvar, D. H. Cerebral Blood Flow during Neurolept Analgesia in the Cat: A Preliminary Study. Acta anaesth. Scandinav. 10: 47 (1965).

9. McIntyke, J. W. R. Awareness during Anaesthesia: Preliminary Observations. Canad. Anaesth. Soc. J. 13: 495 (1966).

10. Eckenhoff, James E.; Kneale, Dorothy H.; \& Dhupps, Robert D. The Incidence and Etiology of Postanaesthetic Excitement: A Clinical Survey. Anesthesiology. 22: 667 (1961).

11. Egbert, L. D.; Lamdin, S. J.; \& Hacrett, T. P. Psychologic Factors Influencing Postoperative Narcotic Administration. Anesthesiology. 28: 246 (1967).

12. Smessaent, Andhe; Schehr, Claire A.; \& Artusio, Joseph E. Observations in the Immediate Postanaesthesia Period. Brit. J. Anaesth. 32: 181 (1960).

13. Есвент, L. D. Reduction of Postoperative Pain by Encouragement and Instruction of Patients: A Study of Doctor-Patient Relationships. New England J. Med. 270: 825 (1964).

14. Dunbar, B. S.; Ovassapian; \& SMith, T. C. Respiratory Effects of Anaesthesia with Innovar and Nitrous Oxide in Man. Anesthesiology. 28: 245 (1967). 